\title{
A IMPORTÂNCIA DO CLIMA ORGANIZACIONAL
}

Tarciza Alves de SOUZA ${ }^{1}$

Dejanir José CAMPOS JÚNIOR ${ }^{2}$

Sérgio Ricardo MAGALHÃES ${ }^{3}$

\begin{abstract}
${ }^{1}$ Acadêmica do curso de MBA em Gestão de Pessoas da Faculdade Pitágoras - Unidade Betim. E-mail tarciza.souza@hotmail.com

${ }^{2}$ Mestre em Educação. Docente do curso de MBA em Gestão de Pessoas e Segurança do Trabalho da Faculdade Pitágoras - Unidade Betim. E-mail: dejanirj@ pitagoras.com.br

${ }^{3}$ Doutor em Métodos Estatísticos Aplicados à Engenharia Biomédica. Docente do curso de Administração da Universidade Vale do Rio Verde - UninCor, campus Betim. E-mail: sergio.magalhaes@unincor.edu.br
\end{abstract}

Recebido em: 17/10/2014 - Aprovado em: 04/06/2015 - Disponibilizado em: 15/07/2015

RESUMO: Em uma época em que a globalização, a competição, o forte impacto da tecnologia e as célebres e rápidas mudanças se tornaram os maiores desafios externos. Nesse contexto, a competitividade nas empresas transparece na maneira de utilizar o conhecimento das pessoas e colocá-lo rápido e eficazmente em ação na busca de soluções satisfatórias e na oferta de novos produtos e serviços inovadores. A transformação do papel das pessoas é a nova revolução que está ocorrendo nas organizações bem sucedidas. Isso decorre de uma nova cultura e de uma nova estrutura organizacional onde se privilegia o capital intelectual e o aporte de valor que somente as pessoas podem proporcionar, desde que devidamente preparadas e motivadas para tal. O presente estudo tem a finalidade de demonstrar como o clima organizacional pode contribuir positivamente para que as pessoas da organização se envolvam com os seus objetivos e gere resultados satisfatórios para a mesma se tornando um elemento essencial e imprescindível para o sucesso da organização. Mas para que isto ocorra é fundamental que as empresas proporcionem aos seus colaboradores um ambiente de trabalho saudável e com um bom clima organizacional.

Palavras-chave: Desafios, pessoas, resultados satisfatórios, ambiente de trabalho, clima organizacional.

\section{THE IMPORTANCE OF ORGANIZATIONAL CLIMATE}

\begin{abstract}
At a time when globalization, the competition, the strong impact of technology and the famous and rapid changes have become the biggest external challenges. In this context the competitiveness of companies transpires in the way of using the knowledge of the people and put it quickly and effectively in action seeking satisfactory solutions and the provision of new innovative products and services. Transforming the role of the people is the new revolution that is occurring in successful organizations. This is because of a new culture and a new organizational structure where it favors the intellectual capital and the value of contribution that only people can provide if properly prepared and motivated to do so. This study aims to demonstrate how the organizational climate can help ensure that people in the organization to get involved with their goals and generate satisfactory results for the same becoming an essential and indispensable element for the success of the organization. But for this to occur it is essential that companies provide their employees with a healthy work environment and a good organizational climate.
\end{abstract}

Key words: Challenges, people, satisfactory results, work environment, organizational climate. 
O mundo está mudando muito rapidamente. Vários fatores contribuem para isso: as mudanças econômicas, tecnológicas, sociais, culturais, legais, políticas, demográficas e ecológicas que atuam de maneira conjugada e sistêmica, em um campo dinâmico de forças que produzem resultados inimagináveis, trazendo imprevisibilidade e incerteza para as organizações.

Diante de tantas mudanças as organizações também estão tendo que mudar suas estratégias e com isto as pessoas passam a significar o diferencial competitivo que mantém e promove o sucesso organizacional: elas passam a constituir a competência básica da organização, a sua principal vantagem competitiva em um mundo globalizado, instável, mutável e fortemente concorrencial. As pessoas passam a constituir o elemento básico do sucesso empresarial (CHIAVENATO, 2010).

Mas para que os resultados que as organizações esperam de seus colaboradores sejam positivos é necessário que estes se sintam em um ambiente de trabalho favorável para tal. O ambiente de trabalho se caracteriza por condições físicas e materiais e por condições psicológicas e sociais. De um lado, os aspectos ambientais que impressionam os sentidos que podem afetar o bem-estar físico, a saúde e integridade física das pessoas. De outro lado, os aspectos ambientais que podem afetar o bem-estar psicológico e intelectual, a saúde mental e a integridade moral das pessoas (CHIAVENATO, 2010). Ainda de acordo com Chiavenato (2010), um ambiente de trabalho agradável facilita o relacionamento interpessoal e melhora a produtividade, bem como reduz acidentes, doenças, absenteísmo e rotatividade de pessoal. Fazer do ambiente um local agradável para se trabalhar tornou-se uma verdadeira obsessão para as empresas bem sucedidas.

Contudo, se torna necessário que a empresa tenha conhecimento do seu clima organizacional bem como os fatores que nele influenciam.

Dessa forma, este estudo tem como objetivo analisar como os fatores que influenciam o clima organizacional podem gerar resultados positivos para a empresa.

Têm-se ainda como objetivos específicos identificar os fatores que influenciam no clima organizacional da empresa; identificar os aspectos relevantes para a busca de satisfação e bem estar dos 
colaboradores; verificar o que aumenta o grau de satisfação e motivação dos funcionários; demonstrar a influência da liderança no clima organizacional.

\section{Clima organizacional}

De acordo com Luz (1996), o clima organizacional é considerado um conjunto de valores e atitudes de padrões de comportamentos existentes em uma organização, que reflete o grau de satisfação das pessoas no trabalho. É o reflexo do estado de espírito ou de ânimo das pessoas em um determinado período.

Para Chiavenato (2004, p. 119) "o clima organizacional é a qualidade ou propriedade do ambiente organizacional que é percebida ou experimentada pelos participantes da organização e influencia o seu comportamento".

"O clima representa o ambiente psicológico e social que existe na organização e que condiciona o comportamento de seus membros." (CHIAVENATO, 2004, p. 99).

Percebe-se que há uma forte ligação entre o clima da organização de forma que quando aumenta a motivação entre os indivíduos, o clima favorável se eleva e se transforma em relação de satisfação, de animação de interesse e que contribuem positivamente tanto para a empresa quanto para seus colaboradores. Diante disso estudos apontam aspectos que podem gerar motivação no ambiente de trabalho e melhorar o seu clima.

Segundo Chiavenato (2004) o ambiente organizacional apresenta certas propriedades que podem provocar motivação para determinados comportamentos sendo que dimensões do clima organizacional são:

- $\quad$ Estrutura organizacional Pode impor limites ou liberdade de ação para as pessoas através de ordem, restrições e limitações impostas na situação de trabalho, como regras, regulamentos, procedimentos, autoridade, especialização etc. Quanto mais liberdade, melhor o clima;

- Responsabilidade - Pode coibir ou pode incentivar o comportamento das pessoas através de dependência do superior, negação da iniciativa pessoal, restrição quanto a decisões pessoais etc. Quanto mais incentivar, melhor o clima organizacional;

- Riscos - A situação de trabalho pode ser essencialmente protetora para evitar riscos ou ser impulsionadora no sentido de assumir desafios novos e 
diferentes. Quanto mais impulsionadora, melhor o clima;

- Recompensas - A organização pode enfatizar críticas e punições, como pode estimular recompensas e incentivos pelo alcance de resultados, deixando o método de trabalho a critério de cada pessoa. Quanto mais estimular recompensas e incentivos, melhor o clima;

- Calor e apoio - A organização pode manter um clima frio e negativo de trabalho como pode criar um clima de calor humano, boa camaradagem e apoio à iniciativa pessoal e grupal;

- Conflito - A organização pode estabelecer regras e procedimentos para evitar choques de opiniões diferentes, como pode incentivar diferentes pontos de vista e administrar os conflitos decorrentes por meio da confrontação. Quanto mais incentivo a diferentes pontos de vista, melhor o clima.

Chiavenato (2004, p. 424), diz: o desempenho e satisfação no trabalho.

Para Bergamini (1997, p. 98), Clima Organizacional nada mais é do que indicador do nível de satisfação (ou insatisfação) experimentado pelos empregados no trabalho.

Entende-se por fatores de satisfação aqueles que demonstram os sentimentos positivos do colaborador em relação ao trabalho.

Para Chiavenato (1994, p. 53), "O clima organizacional é favorável quando proporciona satisfação das necessidades pessoais dos participantes, produzindo elevação do moral interno. É desfavorável quando proporciona frustração daquelas necessidades".

Entende-se por satisfação fatores que demonstram os sentimentos mais positivos do colaborador em relação ao trabalho como: realização, reconhecimento, responsabilidade e progresso.

\subsection{Fatores que podem influenciar o clima organizacional}

Há diversos fatores que podem ter motivação das pessoas e sobre importante é que o clima organizacional tem uma influência poderosa na

[...] serem estas as principais dimensões do clima organizacional. Diferentes climas organizacionais podem ser criados através de variações nessas dimensões. O 
é a cultura organizacional, a motivação, a qualidade de vida no trabalho e a liderança.

\subsubsection{Cultura organizacional}

Pode-se conceituar Cultura organizacional como o conjunto de hábitos, crenças, valores, tradições, interações e relacionamentos sociais típicos de cada organização. Representa a maneira costumeira de pensar e fazer as coisas, e que é compartilhada por todos os membros da organização. A cultura organizacional envolve as normas informais e não escritas que orientam o comportamento dos membros da organização no cotidiano e direcionam suas ações para a realização dos objetivos organizacionais. Cada organização tem a própria cultura corporativa (CHIAVENATO, 2004).

Para Chiavenato (2004) certos aspectos da cultura organizacional são facilmente percebidos enquanto outros são mais ocultos e de diferente percepção assim como um iceberg, ficando os aspectos formais como as políticas e diretrizes, os métodos e procedimentos, objetivos, estrutura organizacional e tecnologia adotada na parte visível. Os aspectos informais que envolvem percepções, sentimentos, atitudes, valores, interações informais e normas grupais, que são de mais difícil compreensão, na parte inferior do iceberg.

Figura 1 Aspectos Formais e Informais da cultura organizacional

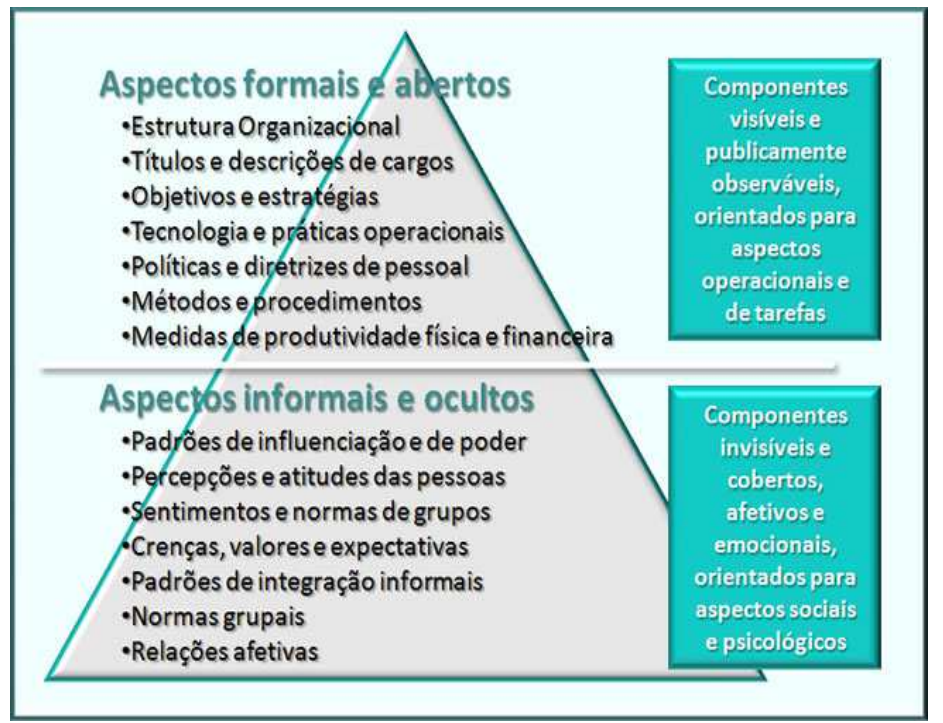

Fonte: Chiavenato (2005, p. 41). 
Katz e Kahn citados por Chiavenato (2010, p.378) salientam que:

cada organização cria a própria cultura com seus tabus, usos e costumes. A cultura do sistema reflete as normas e os valores do sistema formal e sua reinterpretação pelo sistema informal, bem como decorre das disputas internas e externas das pessoas que a organização atrai seus processos de trabalho e distribuição física, as modalidades de comunicação e o exercício da autoridade dentro do sistema. Assim como a sociedade tem uma herança cultural, as organizações sociais possuem padrões distintivos de sentimentos e crenças coletivos, que são transmitidos aos novos membros.

Segundo Chiavenato (2010), a essência da cultura de uma empresa é expressa pela maneira como ela faz seus negócios, trata seus clientes e funcionários, pelo grau de autonomia ou liberdade que existe em suas unidades ou escritórios e pelo grau de lealdade expresso por seus funcionários a respeito da empresa. A cultura organizacional representa as percepções dos dirigentes e colaboradores da organização e reflete a mentalidade que predomina na organização. Mais do que isso, a cultura organizacional é uma forma de interpretação da realidade organizacional e constitui uma modelagem para lidar com questões organizacionais.
Uma boa cultura organizacional e que agrega ao capital humano é aquela "democrática e participativa que inspire confiança, comprometimento, satisfação, espírito de equipe. Uma cultura baseada em solidariedade camaradagem entre as pessoas." (CHIAVENATO, 2010, pag. 53)

Para Luz (2003, p.14):

A cultura organizacional é
constituída de aspectos que dão
às organizações um modo
particular de ser. Ela está para a
organização, assim como a
personalidade está para o
indivíduo. Ela representa o
conjunto de crenças, valores,
estilos de trabalho e
relacionamento que distingue
uma organização das outras. A
cultura molda a identidade de
uma organização, assim como a
identidade e o reconhecimento
dos próprios funcionários.

\subsubsection{Motivação}

A motivação tem sido um tema amplamente estudado na gestão de pessoas e, mesmo assim, continua sendo um dos aspectos mais preocupantes do cotidiano das organizações. Muito se fala, mas, na realidade, pouco se avança. São várias as opções para motivar os empregados, mas rapidamente volta-se à estaca zero. 
"Podemos definir motivação como o processo responsável pela intensidade, direção e persistência dos esforços de uma pessoa para o alcance de uma determinada meta." (ROBBINS, 1999, p. 132).

$\mathrm{O}$ estudo da motivação torna-se necessário para que haja o conhecimento dos mecanismos que movimentam as pessoas e as façam agir em busca de um objetivo que por sua vez, afeta o clima organizacional.

São diversas e amplamente específicas as definições de motivação.

Robbins (1999, p. 132) define motivação como o "processo responsável pela intensidade, direção e persistência dos esforços de uma pessoa para o alcance de uma meta".

Ainda para Robbins (1999, p. 342) “a motivação é a disposição de exercer em nível elevado e permanente de esforço em favor das metas da organização, sob a condição de que o esforço seja capaz de satisfazer alguma necessidade individual”.

Uma das teorias mais lembradas quando se fala em motivação é a proposta apresentada por Abraham Maslow em 1943.

$$
\text { Maslow (1954) concebe a }
$$

motivação como algo constante, infinito e complexo encontrado em todos os seres humanos. O homem é um animal que deseja e que raramente alcança um estado de completa satisfação, exceto durante um curto tempo. À medida que satisfaz um desejo, sobrevém outro que quer ocupar seu lugar. Quando este é satisfeito, surge outro ao fundo. É característica do ser humano, em toda sua vida, desejar sempre algo.

A classificação dos objetivos humanos propostos por Maslow resulta em cinco necessidades que direcionam o comportamento. São elas:

1. Fisiológica: inclui fome, sede, abrigo, sexo e outras necessidades do corpo.

2. Segurança: inclui segurança e proteção contra danos físicos e emocionais.

3. Social: inclui afeição, aceitação, amizade e sensação de pertencer a um grupo.

4. Estima: inclui fatores internos de estima, como respeito próprio, realização e autonomia; e fatores externos de estima, como status, reconhecimento e atenção.

5. Auto-realização: a intenção de tornarem-se tudo aquilo que se é capaz de ser; incluir crescimento, alcance do seu próprio potencial e autodesenvolvimento. 
Figura 2: Pirâmide de Maslow

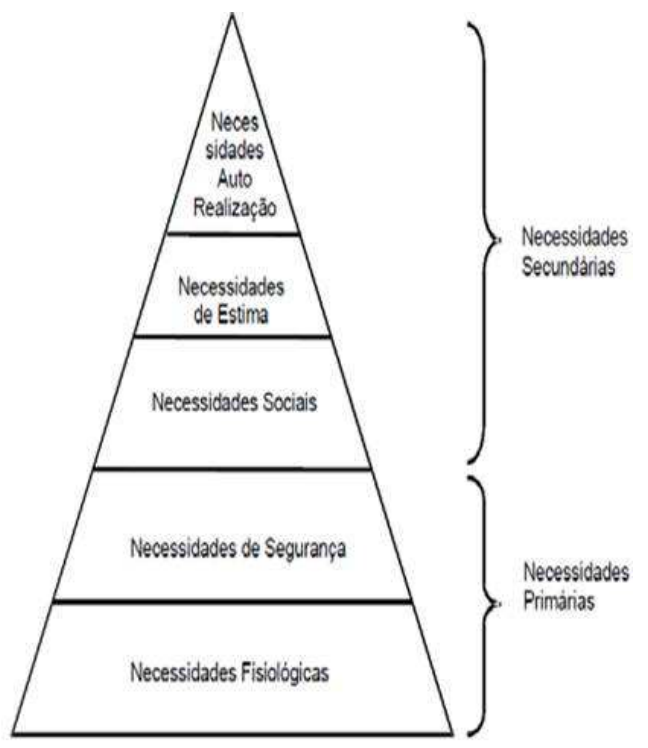

Fonte: Chiavenato (2002, p,)

Maximiano (1997, p.216) fez as seguintes observações sobre a teoria de Maslow:

1. As necessidades básicas manifestam-se em primeiro lugar, e as pessoas procuram satisfazê-las antes de se preocupar com as de nível mais elevado.

2. Uma necessidade de uma categoria qualquer precisa ser atendida antes que a necessidade de outra categoria seguinte se manifeste.

3. Uma vez atendida, a necessidade perde sua força motivadora, e a pessoa passa a ser motivada pela ordem seguinte das necessidades.

4. Quanto mais elevado o nível das necessidades, mais saudável a pessoa é.

5. O comportamento irresponsável é sintoma de privação das necessidades sociais e de estima. $\mathrm{O}$ comportamento negativo é consequência de má administração.

No campo de administração, pessoa motivada significa alguém que demonstre alto grau de disposição para realizar uma tarefa ou atividade de qualquer natureza.

\subsubsection{Motivação: fator intrínseco}

Em sentido mais amplo, na psicologia, motivação corresponde "a modificação do organismo que o faz moverse, até que de reduza essa modificação" (PIÉRON, 1964).

Motivação é entendida como um impulso à ação. É também traduzida como necessidade ou tendência (PIÉRON, 1964). 
Por tratar-se de impulso ou necessidade, é obvio que é originada basicamente no interior dos indivíduos. Assim sendo, a fala comum "você tem que motivar seus empregados!" perde seu uso prático, pois sugere algo impossível de realizar.

Esse equívoco talvez determine a impotência de gestores e organizações ante os aspectos motivacionais das pessoas no trabalho. Dessa forma, é necessário entender mais profundamente os aspectos internos do ser humano (CASADO, 2002).

\subsubsection{Qualidade de vida no trabalho}

O ambiente empresarial tem buscado a competitividade em virtude das profundas mudanças ocorridas na economia mundial, nas relações sociais e políticas, na tecnologia, na organização produtiva e nas relações de trabalho. Todas essas mudanças geram um ambiente socioempresarial em ebulição, no qual os fatores conjunturais de sobrevivência muitas vezes se sobrepõem aos objetivos de mudanças de longo prazo na sociedade que conduzam, efetivamente, a melhorias de condições de vida e bemestar dos cidadãos (LIMONGI-FRANÇA, 2002; ARELIANO, 2002).
Segundo Albuquerque (1999), dentro desse contexto, no qual as organizações buscam produtividade e processos de mudanças que tenham o objetivo de melhorar seu posicionamento competitivo no mercado, a qualidade de vida no trabalho (QVT) vem ganhando espaço como valor intrínseco das práticas de competitividade concomitantemente ao bem-estar organizacional.

Qualidade de vida no trabalho é um conceito que se refere aos aspectos da experiência do trabalho, como estilo de gestão, liberdade e autonomia para tomar decisões, ambiente de trabalho agradável, camaradagem, segurança no emprego, horas adequadas ao trabalho e tarefas significativas e agradáveis. "Um programa de QVT procura estruturar o trabalho e o ambiente no sentido de satisfazer a maioria das necessidades individuais das pessoas e tornar a organização um local desejável e atraente" (CHIAVENATO, 2010, p. 13).

$$
\text { Para Limongi-França (1996), }
$$
qualidade de vida no trabalho é o conjunto das ações de uma empresa no sentido de implantar melhorias e inovações gerenciais, tecnológicas e estruturais no ambiente de trabalho. 
momento em que se olha a empresa e as pessoas como um todo, o que chamamos de enfoque biopsicossocial e posicionamento.

Biopsicossocial representa o fator diferencial para realização de diagnóstico, campanhas, criação de serviços e implantação de projetos voltados para preservação e desentendimento das pessoas, durante o trabalho na empresa (LIMONGI-FRANÇA， 1997, p. 80).

"O conceito de qualidade de vida no trabalho tem sido avaliado e questionado através dos anos, definindo-se não como modismo passageiro, mas como processo que consolida a busca do desenvolvimento humano e organizacional". (LIMONGIFRANÇA, BERNAL, 2002, p. 297).

Se a qualidade de vida no trabalho for pobre, conduzirá à alienação do empregado e à insatisfação, à má vontade, ao declínio da produtividade, a comportamentos

contraproducentes (como absenteísmos, rotatividade, roubo, sabotagem, militância sindical etc). Qualidade do trabalho elevada conduz a um clima de confiança e respeito mútuo, no qual as pessoas tendem a aumentar suas contribuições e elevar suas oportunidades de êxito psicológico enquanto a administração tende a reduzir mecanismos rígidos de controle social (CHIAVENATO, 2010, p. 488).

Por outro lado, a importância das necessidades humanas varia conforme a cultura de cada indivíduo e de cada organização. Portanto, a QVT não é determinada apenas por características individuais ou situacionais, mas também pela atuação sistêmica dessas características individuais e organizacionais (CHIAVENATO, 2010).

A qualidade de vida na organização influencia no clima organizacional que por sua vez influencia o desempenho de seus colaboradores e assim atingindo negativamente (se insatisfeitos) ou positivamente (se motivados) na produtividade dos indivíduos.

De acordo com Bennett (1983), a melhora da produtividade não pode ser discutida sem o reconhecimento de que o conceito de produtividade vai além da ideia de uma boa produção ou de eficiência no trabalho sendo este é um conceito que encontra raízes no dinamismo humano por ter uma conexão indispensável com a melhoria da natureza e a qualidade de vida de cada indivíduo no trabalho.

Segundo Limongi-França e Areliano (2002), a melhora da produtividade significa motivação, dignidade, participação no desenho e no desempenho do trabalho na organização. Significa desenvolver 
indivíduos cujas vidas podem ser produtivas em todos os sentidos.

Hoje as organizações não têm visto a qualidade de vida apenas como um aspecto para aumentar a produtividade e sim como um fator que gere mais satisfação do indivíduo bem como a melhora do clima organizacional.

"Durante muito tempo, ao falar-se em qualidade de vida nas empresas, enfatizava-se principalmente a produção" (GIL, 2001, p. 46). A produção foi vista por muito tempo como um fator que refletia a qualidade de uma empresa, sempre em busca de mais produtividade e aumento dos lucros.

Mas para que tal mudança seja percebida pelos colaboradores as organizações vêm se adequando a este conceito para aumentar não somente a produção, mas também para melhorar a satisfação, a motivação, diminuir a rotatividade, prejuízos dentre outros benefícios que somados podem ser capazes de refletir até na expectativa de vida de uma organização. "Hoje, fala-se não apenas em qualidade no trabalho, mas também em qualidade de vida dos empregados" (GIL, 2001, p. 46).
Estratégias para aumentar a qualidade de vida no trabalho contribuem para um "subproduto essencial da melhora da produtividade, uma vez que estão relacionadas com a qualidade de experiência humanas no ambiente de trabalho que envolve o trabalho em si, o ambiente de trabalho e a personalidade do empregado"

(LIMONGI-FRANÇA; BERNAL, 2002, p. 301).

\subsection{Liderança}

A liderança é um processo social no qual se estabelecem relações de influência entre pessoas. O núcleo desse processo de interação humana é composto do líder ou líderes, seus liderados, um fato e um momento social.

Segundo Robbins (2005), liderança é a capacidade de influenciar um grupo para alcançar metas. A origem dessa influência pode ser formal, como a que é conferida por um alto cargo na organização. Como essas posições subentendem certo grau de autoridade, uma pessoa pode assumir um papel de liderança apenas em função do cargo que ocupa.

“A liderança é necessária em todos os tipos de organização humana, seja nas empresas, seja em cada um de seus 
departamentos" (CHIAVENATO, 2004, p. 100).

Hollander (1978) conceitua liderança como um processo que envolve relacionamento de influência em duplo sentido, orientado principalmente para o atendimento de objetivos mútuos, tais como aqueles de um grupo, organização ou sociedade. Segundo o autor, a liderança não diz respeito apenas ao cargo do líder mas também requer a cooperação de outras pessoas.

Vergara (1999) afirma que a liderança está associada a estímulos e incentivos que podem motivar as pessoas para realização da missão, da visão e dos objetivos empresariais.

Liderança é um processo no qual o líder busca, sob influência e aceitação do próprio grupo, o alcance de metas e objetivos específicos através de mobilização, motivação, informação e comunicação, manejo e solução de conflitos, estabelecimento de estratégias e definição de políticas. A liderança também é exercida quando há intenção de direcionar a aceitação dos seguidores em ser liderados. Não existe um líder universal e a própria História é exemplo dessa constatação. O líder só se mantém líder enquanto estiver atendendo às expectativas e às necessidades de seus liderados e grupos relacionados com o processo de influência em que está inserido. (LIMONGI-FRANÇA, BERNAL, 2002, p. 267-268).

Segundo Chiavenato (2004) há várias teorias diferentes sobre os diferentes estilos de diferentes sendo que os estilos mais conhecidas referem-se à liderança autocrática, liberal e democrático.

Liderança autocrática: O líder centraliza as decisões e impõe ordens ao grupo. $\mathrm{O}$ comportamento do grupo demonstra forte tensão, frustração e agressividade, de um lado e de outro, nenhuma espontaneidade, iniciativa e formação de grupos de amizade. O trabalho só se desenvolve com a presença física do líder.

Liderança liberal: O líder delega totalmente as decisões ao grupo e os deixa totalmente à vontade e sem controle nenhum. As tarefas se desenvolvem ao acaso, com muitas oscilações.

Liderança democrática: $\mathrm{O}$ líder conduz e orienta o grupo e incentiva a participação democrática das pessoas. Geralmente os grupos formados apresentam melhor relacionamento de amizade e cordialidade entre os membros. O trabalho desenvolve-se em ritmo suave e seguro, 
sem alteração, com ou sem a presença do líder.

Diante dos diferentes estilos de liderança o principal desafio dos líderes é saber quando aplicar qual estilo, com quem e em que circunstâncias de modo que haja sempre um clima agradável entre líderes e liderados, e, consequentemente, influenciar de forma positiva no envolvimento da equipe para o alcance dos objetivos da empresa contribuindo, assim, para um bom clima organizacional.

\subsection{Avaliação do clima organizacional}

A principal forma de tornar o clima organizacional mensurável é através da pesquisa de clima. Segundo Luz (1996), a pesquisa de clima tem a finalidade identificar e avaliar as atitudes e os padrões de comportamento, com vistas a orientar políticas de ações e correção de problemas no relacionamento e no plano motivacional dos integrantes da organização. Trata-se da busca para detectar imperfeições existentes nas relações que impactam nos resultados da organização, a fim de corrigi-las.

Ainda de acordo com Luz (2003), a pesquisa de clima organizacional é um canal de comunicação entre a direção e os demais colaboradores tendo a capacidade de promover um crescimento nas relações do trabalho, auxiliando na missão de melhorar o ambiente organizacional, transformando os diferentes aspectos que podem alavancar o sucesso da empresa.

Uma pesquisa de clima quando bem realizada e incorporada em ações concretas, proporciona às pessoas um bom ambiente de trabalho, apresenta oportunidade de aumentar os resultados da organização, contribui para a melhoria do desempenho dos colaboradores, além de proporcionar mudanças na atitude das pessoas em ralação á organização que integram. Um clima saudável possibilita às pessoas executar suas tarefas de modo mais eficiente e eficaz. A análise do clima organizacional, por sua vez, converte-se, neste contexto, em instrumento de avaliação de gestão de política de desenvolvimento organizacional (TACHIZAWA; FERREIRA;FORTUNA, 2004).

A pesquisa científica pode ser definida como um procedimento racional e sistemático que tem como objetivo proporcionar respostas aos problemas que são propostos. É requerida quando não se dispõe de informação suficiente para responder ao problema, ou então quando a informação disponível se encontra em tal 
estado de desordem que não possa ser adequadamente relacionada ao problema.

\section{Considerações finais}

Vivemos hoje em um mundo globalizado e neste nos encontramos em constantes mudanças. No mundo organizacional não tem sido diferente e estas constantes mudanças têm exigido cada vez mais qualificação, determinação e envolvimento de seus colaboradores para que as metas da organização sejam alcançadas. Como demonstrado no atual estudo o clima organizacional e seus diferentes aspectos que exerce influência sobre o mesmo tem grande relevância nesta busca para alcançar os objetivos da organização.

Através do estudo podemos perceber que o um bom ambiente de trabalho, com uma equipe motivada, uma boa qualidade de vida na empresa e uma liderança eficaz é capaz de melhorar o ambiente que se estão inseridos e, consequentemente, melhorar a produtividade da equipe.

É de suma importância que em todas as organizações haja um ambiente de trabalho amistoso que proporcione trocas agradáveis, harmoniosas e sadias entre as pessoas para que estas trabalhem satisfeitas e motivadas em busca do sucesso. Para que isto ocorra é muito importante que a Gestão de Pessoas das empresas esteja em constante análise do ambiente organizacional, sempre em busca de melhorias contínuas. Dentre os fatores apresentados cada um tem sua colaboração para melhoria do clima:

A cultura organizacional contribui para a melhoria do clima com a afirmação de suas crenças valores, forma de tratamento, envolvimento e comunicação com seus colaboradores;

A motivação é a chama que todos os gestores têm o desafio de mantê-la acessa sem que as pessoas da equipe percam o interesse e o foca da sua missão;

A liderança agrega à melhoria do clima organizacional trazendo confiança entre os membros da equipe como um todo mobilizando e motivando os para atingir os objetivos almejados;

Já a qualidade de vida é algo indispensável para os colaboradores uma vez que, em geral, a população passa um terço do dia no ambiente de trabalho. A QVT busca sempre reduzir o nível de stress dos colaborados e aumentar a sua satisfação no trabalho. 
Através do estudo e junção desses aspectos acreditamos que podemos alcançar um clima organizacional positivo com um forte envolvimento e comprometimento da equipe de trabalho em busca que busca todas as organizações: o sucesso.

\section{Referências}

LIMONGI-FRANÇA, A. C. A expansão do conceito QVT: do estresse à qualidade total. Rausp, São Paulo, 1999.

As pessoas na organização. São

Paulo: Editora Gente, 2002.

BENNETT, A. C. Productivity and the quality of work life in hospitals.

Publishing, 1983.

BERGAMINI, Cecília W. Motivação nas organizações. 4. ed. São Paulo: Atlas, 1997.

CASADO, Tânia. As pessoas na organização. São Paulo: Editora Gente, 2002.

CHIAVENATO, Idalberto. Gestão de Pessoas. 3. ed. rev. e atual. - Rio de Janeiro: Elsevier, 2010.

\section{Introdução à Teoria Geral da}

Administração. 3. ed. rev. e atualizada Rio de Janeiro : Elsevier, $2004-2^{\mathrm{a}}$

Reimpressão.

Gerenciando Pessoas. 3 ed. São

Paulo. Makron books, 1994.
GIL, Antônio Carlos. Gestão de Pessoas: Enfoque nos papéis profissionais. São Paulo: Atlas, 2001.

HOLLANDER, E. P. Leadership dynamics: a practical guide to effective relationships. New York: The Free Press, 1978.

\section{LUZ, Ricardo Silveira. Clima}

Organizacional. Rio de Janeiro:

Qualitymark, 1996.

Clima Organizacional. Rio de

Janeiro: Qualitymark, 2003.

MASLOW, Abraham H. Motivation and personality. USA: Harper Brothers, 1954.

MAXIMIANO, A. C. A. Introdução à Administração. 7. ed. São Paulo: Atlas, 2007.

PIÉRON, Henri. Dicionário de Psicologia. Buenos Aires: Editora Kapelusz, 1964.

ROBBINS, Stephen P. Administração: mudanças e perspectivas. São Paulo: Saraiva, 2000.

\section{Comportamento Organizacional.}

Rio de Janeiro: LTC, 1999.

TACHIZAWA, Takeshy; FERREIRA, Victor Cláudio Paradela; FORTUNA, Antônio Alfredo Melo. Gestão de Pessoas: Uma abordagem aplicada às estratégias de negócios, 4 ed. Ver, e atual - Rio de Janeiro: Editora FGV, 2004.

VERGARA, S. C. Gestão de pessoas. São Paulo: Atlas, 1999. 